\title{
The role of the expert witness in court
}

The use of an 'itinerant' expert witness in our civil courts used to be confined mostly to the field of forensic pathology, but has now become established in radiology. Doctors are often accused of closing ranks in malpractice claims against colleagues by a patient. In my experience, radiologists invariably have been balanced and responsible when asked to comment on malpractice issues; in 40 years of practise, I have never seen or heard of a deliberate cover-up to protect a colleague's interests above those of a patient.

The itinerant radiology expert, however, represents a totally new and, to us in South African practise, foreign development: an 'expert' witness traveling from one provincial High Court to the next involving some sort of litigation against a colleague (usually a fellow radiologist) and often concerning advanced CT or MRI neuro-imaging issues.

I asked my good friend, the world-renowned forensic pathologist, Professor Deon Knobel, to discuss some issues regarding the radiologist and the law. As usual, he goes to the nub of the matter: the need for a non-partisan witness for the truth.

\section{Jan Lotz}

Editor-in-chief

The role of the expert witness in court has been a point for discussion in medical and legal circles for many decades. The expert witness is called to give evidence and an opinion on specialised fields of medicine and other scientific and professional disciplines and is also often expected to listen to and interpret the evidence of colleagues, and afterwards to express an opinion to the court. The expert may also be appointed as assessor to assist the presiding officer in the interpretation and evaluation of scientific evidence.

It is not necessary for me to remind you of some of the incidents of civil litigation by patients whose permanent injury or death was caused by treatment rendered and where the doctor became the defendant. Under such circumstances, the role of the expert witness becomes invaluable; I have collected numerous examples in my own career of 40 years in forensic medicine, in some of which the 'expert evidence' given was highly questionable.

\section{The need for peer review}

The opinions of historical figures such as Sir Bernard Spilsbury - and even men like the late Professor Milton Helpern from New York, and Hillel Shapiro of South Africa, who practised 'the art of forensic medicine' - were accepted as holy fact. Professor Hugh Johnson of London expresses himself on this topic as follows:

'I hope, though, that we will never go back to the expert having the status that the late Sir Bernard Spilsbury enjoyed; whose evidence, when he was in his prime, was accepted as having the authority of holy writ and there was seldom any effective opposition from the other side ${ }^{22}$

In contrast, we in modern forensic medicine have become aware of its multidisciplinary character and, at formal inquests enquiring into the circumstances of death associated with medical care such as surgery or anaesthetics and other therapeutic mishaps, advise the magistrate more and more to make use of specialists in each field to assist him as an assessor or expert witness. We hope thus eventually to reach the stage where peer review and professional assessment of our medical skills will lead to improvement of medicine and better service to the patient. ${ }^{1}$

Too often a phenomenon described by Raanon Gillon as follows, occurs in court:

'... doctors ... have a tendency to close ranks in their own individual and group interests and against the interest of our patients to an extent that is incompatible with our professed adherence to a principle of benefiting our patients. We have had inculcated into us throughout our professional training and socialisation a sort of public school ethos that we do not "split" about a colleague even if we know that the colleague has made a damaging mistake or is frankly incompetent. ${ }^{3}$

I also wish to venture the opinion that the adversarial approach of our South African legal system may be to blame here. Despite the fact that an inquest is not a trial, the finding at the inquest may yet lead to prosecution of or litigation against a health care worker. Therefore, the attitude of witnesses and expert witnesses alike is very often still that of giving evidence 'for the accused' or 'for the defence'. Lundberg, an eminent authority, expressed the position eloquently in the following question:

'Expert witness for whom? Expert witness for the prosecution? Expert witness for the defence? Expert witness for the court? How about unbiased expert witness for the truth?'

In theory, all such experts seek the truth and, while under oath in court, must speak the truth; however, it is very difficult for any person who has grown up in a system of 'sides' on the football field or in the debating hall not to share an advocacy position when their services have been secured by legal counsel committed to such advocacy.

Should not the best experts be available to the court simply to assist in arriving at the correct verdict so that justice, society and the individuals concerned are properly served?

Current American Medical Association policy on medical expert witnesses states that 'the physician should not allow himself to become an advocate or a partisan in the trial [inquest proceedings]. He has a responsibility not to withhold, conceal or distort information. He should not slant or twist his medical opinion. The physician should maintain scientific objectivity.'

Professor Bernard Ackerman, a well-known dermatopathologist of New York, states: 'There is an urgent need to reassess the role of the physician, and particularly that of the pathologist, in the courtroom.

'Irrespective of the behavior in court of lawyers (who take no oath comparable to that of Hippocrates, and who are often fiercely engaged in adversarial relationships), physicians should not be advocates of either a prosecutor or a defence lawyer - but of the unvarnished truth.

continued on page 5 